\title{
The timed up and go test in idiopathic normal pressure hydrocephalus: a Nationwide Study of 1300 patients
}

\author{
Nina Sundström ${ }^{1 *}$ (D) Johanna Rydja², Johan Virhammar ${ }^{3}$, Lena Kollén ${ }^{4}$, Fredrik Lundin ${ }^{4}$ and Mats Tullberg ${ }^{5}$
}

\begin{abstract}
Background: The aim of this study was to describe the outcome measure timed up and go (TUG) in a large, nationwide cohort of patients with idiopathic normal pressure hydrocephalus (iNPH) pre- and post-operatively. Furthermore, to compare the TUG test to the 10-m walk test (10MWT), the iNPH scale, the modified Rankin scale (mRS) and the Mini Mental State Examination (MMSE), which are commonly applied in clinical assessment of iNPH.

Methods: Patients with iNPH $(n=1300)$, registered in the Swedish Hydrocephalus Quality Registry (SHQR), were included. All data were retrieved from the SHQR except the 10MWT, which was collected from patient medical records. Clinical scales were examined pre- and 3 months post-operatively. Data were dichotomised by sex, age, and preoperative TUG time.

Results: Preoperative TUG values were 19.0 [14.0-26.0] s (median [IQR]) and 23 [18-30] steps. Post-operatively, significant improvements to 14.0 [11.0-20.0] s and 19 [15-25] steps were seen. TUG time and steps were higher in women compared to men $(p<0.001)$ but there was no sex difference in improvement rate. Worse preoperative TUG and younger age favoured improvement. TUG was highly correlated to the 10MWT, but correlations of post-operative changes were only low to moderate between all scales $(r=0.22-0.61)$.

Conclusions: This study establishes the distribution of TUG in iNPH patients and shows that the test captures important clinical features that improve after surgery independent of sex and in all age groups, confirming the clinical value of the TUG test. TUG performance is associated with performance on the 10MWT pre- and post-operatively. However, the weak correlations in post-operative change to the 10MWT and other established outcome measures indicate an additional value of TUG when assessing the effects of shunt surgery.
\end{abstract}

Keywords: Timed up and go, Idiopathic normal pressure hydrocephalus, Outcome measure, 10-m walk test, Shunt surgery, Improvement rate

\section{Introduction}

Idiopathic normal pressure hydrocephalus (iNPH) is a syndrome characterised by a triad of gait and balance disturbance, cognitive impairment, and urinary incontinence [1]. iNPH usually presents in elderly individuals.

${ }^{*}$ Correspondence: nina.sundstrom@umu.se

${ }^{1}$ Department of Radiation Sciences, Radiation Physics, Biomedical Engineering, Umeå University, Umeå, Sweden

Full list of author information is available at the end of the article
In persons aged 65 years and older the prevalence has been found to be in the range of $1.3-4 \%[2,3]$. The disorder is treated by shunt surgery, and if carefully selected, $70-80 \%$ of patients improve after surgery, mainly in their gait and balance but also in cognitive function and urinary continence [4].

To assess preoperative levels of the cardinal symptoms as well as post-operative outcome, different scales or other measures of gait, balance control, cognition, incontinence, and activities of daily living are used [5, original author(s) and the source, provide a link to the Creative Commons licence, and indicate if changes were made. The images or other third party material in this article are included in the article's Creative Commons licence, unless indicated otherwise in a credit line to the material. If material is not included in the article's Creative Commons licence and your intended use is not permitted by statutory regulation or exceeds the permitted use, you will need to obtain permission directly from the copyright holder. To view a copy of this licence, visit http://creativecommons.org/licenses/by/4.0/. The Creative Commons Public Domain Dedication waiver (http://creativeco mmons.org/publicdomain/zero/1.0/) applies to the data made available in this article, unless otherwise stated in a credit line to the data. 
6]. Composite scales based on several of these measures, such as the iNPH scale [7], have been introduced in attempts to give a more comprehensive description of the full clinical picture. However, drawbacks are that these scales are time consuming, might require several specialists to complete and are generally blunt when assessing minor improvement. For assessment of function in activities of daily living the modified Rankin scale (mRS) [8], which is an ordinal scale, is commonly used although mRS was not developed for iNPH. The Mini Mental State Examination (MMSE) is commonly used for assessment of cognitive function [9].

Since improvement is seen predominately in gait function [10], outcome assessment in this domain is especially important. One simple and commonly used measurement is the $10 \mathrm{~m}$ walking test (10MWT) where the patient is asked to walk at his/her normal pace for $10 \mathrm{~m}$. The output is simply the time needed to complete the task.

Another test that resembles the 10MWT in simplicity and execution is the Timed Up and Go (TUG) test [11, 12]. This test has primarily been used to estimate risk of falling in elderly populations [13, 14], and incorporates components of gait and balance control. The test is considered to be more comprehensive than the 10MWT [12]. For the TUG test, patients are instructed to get up from an armchair, walk $3 \mathrm{~m}$ at a safe and comfortable pace, turn around, walk back to the chair and sit down [11].

Despite the potential benefit of the TUG test, it is not as commonly used as the 10MWT to measure baseline symptomatology or outcome in patients with iNPH. Although several studies have reported the clinical value of the test [15-18], patients' performance has not been described in a large iNPH population, and the range of post-operative change has not been thoroughly investigated.

The purpose of this study was to evaluate the TUG test including distributions and differences between sexes and age groups in a nationwide, large, non-selected and prospectively collected group of iNPH patients pre- and post-operatively. Furthermore, to investigate the associations between the TUG time and steps and performance in the 10MWT, the modified iNPH (miNPH) scale, mRS and MMSE in patients with iNPH.

\section{Material and methods}

\section{Data retrieval}

Data were collected from the Swedish Hydrocephalus Quality Registry (SHQR). The registry, described in previous publications [19-21], was established in 2004 and prospectively includes $\sim 95 \%$ of all patients aged 18 years or older operated on due to hydrocephalus in one of the seven hydrocephalus centres in Sweden. During two different time periods, two centres put their inclusion on hold due to limited economic resources, reducing the total national coverage during this 16 -year period to $80 \%$. The registry contains information on clinical features of the patients preoperatively as well as three and 12 months and two, five and 10 years post-operatively. Adverse events and possible shunt revisions are also included. For validation of data, audits between centres during the first years following the registry start-up as well as during 2017-2018 and 2020-2021 were performed. Also, dedicated personnel at each centre who registered all information in a structured way ensured the high quality of the included data.

For this study, information on age, sex, date of surgery, components of a modified version of the iNPH scale introduced by Hellstrom (i.e. the ordinal scale scores of gait, balance control and incontinence) [7], mRS score, MMSE score as well as outcome on the TUG test [11] in time $\left(\mathrm{TUG}_{\text {time }}\right)$ and number of steps $\left(\mathrm{TUG}_{\text {steps }}\right)$ were gathered from the SHQR. For details on the ordinal scales see Table 1 . The TUG test was added as a variable in the SHQR in 2010, thus only patients operated on between January 1, 2010 and January 20, 2020 (date of data extraction) were included. Preoperative as well as postoperative data (collected approximately 3 months after surgery) were retrieved. The 10MWT was not included in the SHQR until 2018, thus the time and number of steps during the $10 \mathrm{MWT}(10 \mathrm{MWT}$ time and $10 \mathrm{MWT}$ steps respectively) were collected from local research databases or patients' charts at four of the seven centres. Both the TUG test and 10MWT were, if required, performed with the patients' usual walking aids.

\section{Study population}

In this study, 1300 patients were included. Inclusion criteria were diagnosis of iNPH according to international criteria [22] and registered performance on the TUG test both pre- and post-operatively. In total, 51 patients (22/29 women/men, age 76.4 (6.0) years) performed more than $80 \mathrm{~s}$ or steps in TUG (median $\mathrm{TUG}_{\text {time }}+4 \times$ interquartile range). To avoid the potentially large influence of these subjects which were considered as outliers, on statistical analyses of the main group, they were excluded from the main analyses and instead described as an entity on its own. The selection/division process is shown in Fig. 1. The main group thus consisted of 1249 patients with a mean (SD) age of 74.7 (6.0) years (505 females (40.5\%), 74.8 (6.1) years, and 744 males, 74.7 (6.0) years).

\section{Outcome scales and comparisons}

Until recently, the SHQR did not incorporate all parameters in the four domains included in the original iNPH 
Table 1 Clinical grading scales

\begin{tabular}{|c|c|c|c|c|}
\hline Score & Gait & Balance & Urinary incontinence & $\mathrm{mRS}$ \\
\hline 0 & & & & No symptoms \\
\hline 1 & Normal & $\begin{array}{l}\text { Stands independently for } \geq 30 \mathrm{~s} \\
\text { on either lower extremity alone }\end{array}$ & Normal & $\begin{array}{l}\text { No significant disability. Able to } \\
\text { carry out all usual activities, despite } \\
\text { some symptoms }\end{array}$ \\
\hline 2 & $\begin{array}{l}\text { Slight disturbance of tandem } \\
\text { walk and turning }\end{array}$ & $\begin{array}{l}\text { Stands independently for }<30 \mathrm{~s} \\
\text { on either lower extremity alone }\end{array}$ & Urgency without incontinence & $\begin{array}{l}\text { Slight disability. Able to look after } \\
\text { own affairs without assistance, but } \\
\text { unable to carry out all previous } \\
\text { activities }\end{array}$ \\
\hline 3 & $\begin{array}{l}\text { Wide-based gait with sway, with- } \\
\text { out foot corrections }\end{array}$ & $\begin{array}{l}\text { Stands independently for } \geq 30 \mathrm{~s} \\
\text { with the feet together at the } \\
\text { heels }\end{array}$ & $\begin{array}{l}\text { Infrequent incontinence without } \\
\text { napkin }\end{array}$ & $\begin{array}{l}\text { Moderate disability. Requires some } \\
\text { help, but able to walk unassisted }\end{array}$ \\
\hline 4 & $\begin{array}{l}\text { Tendency to fall, with foot cor- } \\
\text { rections }\end{array}$ & $\begin{array}{l}\text { Stands independently for }<30 \mathrm{~s} \\
\text { with feet together at the heels }\end{array}$ & $\begin{array}{l}\text { Frequent incontinence with } \\
\text { napkin }\end{array}$ & $\begin{array}{l}\text { Moderately severe disability. Unable } \\
\text { to attend to own bodily needs } \\
\text { without assistance, and unable to } \\
\text { walk unassisted }\end{array}$ \\
\hline 5 & Walking with cane & $\begin{array}{l}\text { Stands independently for } \geq 30 \mathrm{~s} \\
\text { with the feet apart (one foot } \\
\text { length) }\end{array}$ & Bladder incontinence & $\begin{array}{l}\text { Severe disability. Requires constant } \\
\text { nursing care and attention, bedrid- } \\
\text { den, incontinent }\end{array}$ \\
\hline 6 & Bi-manual support needed & $\begin{array}{l}\text { Stands independently for }<30 \text { s } \\
\text { with the feet apart }\end{array}$ & Bladder and bowel incontinence & Dead \\
\hline 7 & Aided & $\begin{array}{l}\text { Unable to stand without assis- } \\
\text { tance }\end{array}$ & Indwelling urinary catheter & \\
\hline 8 & Wheelchair bound & & & \\
\hline
\end{tabular}

Clinical criteria for ordinal scale assessment of function in gait, balance and urinary incontinence (i.e. the components of the modified iNPH scale) as well as mRS

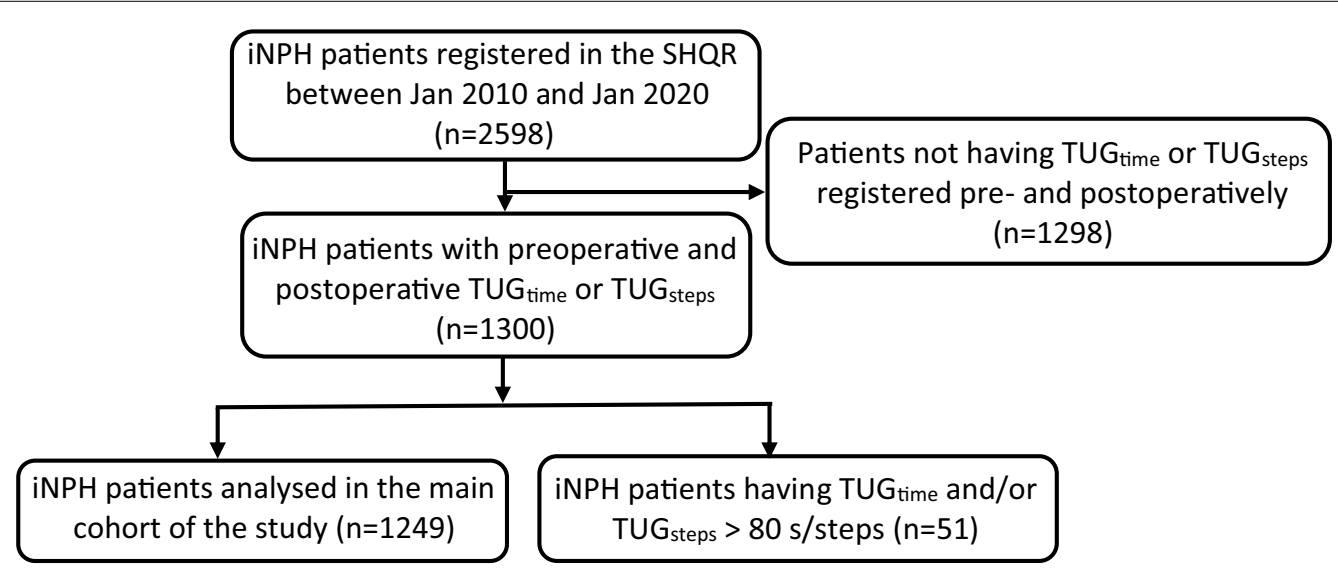

Fig. 1 Study flow chart

scale, thus, a modified version (the miNPH scale) was applied. The miNPH scale has previously been introduced when studying outcome based on data from the SHQR [20], and the only differences compared to the original scale are that the neuropsychological tests and the 10MWT have been excluded. In the original iNPH scale, the 10MWT is part of the gait domain. The gait, balance control and continence test results are converted into domain scores ranging between 0 and 100 and the miNPH total score is calculated according to Eq. (1). [7]

$$
\frac{2 \times \text { Gait } \pm \text { Balance } \pm \text { Continence }}{4(\text { or number of available domain scores })} .
$$

Pre- and post-operative levels as well as post-operative changes in TUG, 10MWT, miNPH scale and mRS were calculated and correlated pairwise. Patients were dichotomised by sex, age $(<70,70 \leq \mathrm{x}<80$ and $\geq 80$ years $)$ and according to preoperative TUG time $\left(\mathrm{TUG}_{\text {time }}<13.5 \mathrm{~s}\right.$, and $\mathrm{TUG}_{\text {time }} \geq 13.5 \mathrm{~s}$ ). This threshold was chosen since a $\mathrm{TUG}_{\text {time }} \geq 13.5 \mathrm{~s}$ has been associated with an increased risk of falling [23]. 


\section{Statistics}

Statistical analyses were performed with PASW Statistics (version 25, IBM SPSS Statistics). Shapiro-Wilk's test was used for testing normality distribution and Spearman correlation for investigating relationships between variables. A correlation coefficient $(\mathrm{r})$ of $0.9-1.0$ signified a very high correlation, $0.7-0.9$ high, $0.5-0.7$ moderate, $0.3-0.5$ low and $0.0-0.3$ a negligible correlation between variables [24]. The Wilcoxon Signed rank test and the Kruskal-Wallis test/MannWhitney U test were used for comparisons between dependent and independent groups, respectively. Statistical significance was set at $\mathrm{p}<0.05$.

\section{Ethical considerations}

The regional ethical review board in Umea approved the study (Dnr 2018-444-31M). In accordance with Swedish legislation and regulations regarding patient consent for participation in a national quality registry, patients are informed about their inclusion in the registry before undergoing surgery. They can opt out of inclusion at any time.

\section{Results}

Pre- and post-operative TUG (for the main group and the outliers as well as by sex and age) and 10MWT time and steps are displayed in Table 2 and Fig. 2. Post-operatively, there was a significant improvement in TUG

Table 2 Preoperative, post-operative and change in TUG time and steps pre-/post-operatively

\begin{tabular}{|c|c|c|c|c|c|c|c|c|}
\hline \multirow[t]{2}{*}{ Group } & \multirow[t]{2}{*}{ Age group } & \multirow{2}{*}{$\begin{array}{l}\mathrm{N} \\
\text { Preop/post-op/ } \\
\text { improvement }\end{array}$} & \multicolumn{2}{|c|}{ Preoperative values } & \multicolumn{2}{|c|}{ Post-operative values } & \multicolumn{2}{|l|}{ Improvement (\%) } \\
\hline & & & Median [Q1, Q3] & Mean $[S D]$ & Median [Q1, Q3] & Mean [SD] & Median [Q1, Q3] & Mean [SD] \\
\hline \multicolumn{9}{|l|}{ Stratified by sex } \\
\hline TUG time total & All & 1249 & $19.0[14.0,26.0]$ & $22.2[12.1]$ & $14.0[11.0,20.0]$ & $16.9[9.2]$ & $21.7[2.9,36.8]$ & $17.6[32.5]$ \\
\hline $\mathrm{TUG}_{\text {time }}$ women & All & 505 & $20.0[15.0,28.5]$ & 23.6 [12.2] & $16.0[12.0,21.0]$ & $17.7[8.8]$ & $22.2[4.1,38.5]$ & $18.6[31.7]$ \\
\hline $\mathrm{TUG}_{\text {time }}$ men & All & 744 & $18.0[14.0,25.0]$ & $21.2[11.9]$ & $13.5[11.0,19.0]$ & $16.4[9.4]$ & $21.5[2.6,36.4]$ & $17.0[33.1]$ \\
\hline TUG steps total & All & $1226 / 1243 / 1227$ & $23.0[18.0,30.0]$ & $26.0[11.4]$ & $19.0[15.0,25.0]$ & $21.1[8.9]$ & $16.7[0.0,31.0]$ & 14.7 [26.9] \\
\hline $\begin{array}{l}T U G_{\text {steps }} \\
\text { women }\end{array}$ & All & 496/503/495 & $24.0[19.0,32.0]$ & $26.8[10.7]$ & $20.0[16.0,26.0]$ & $21.9[7.9]$ & $16.7[0.0,30.0]$ & $14.3[25.1]$ \\
\hline TUG steps $m e n$ & All & 733/740/732 & $22.0[18.0,29.0]$ & $25.5[11.8]$ & $18.0[15.0,24.0]$ & $20.6[9.4]$ & $17.2[3.9,31.1]$ & $15.0[28.0]$ \\
\hline $\begin{array}{l}10 \mathrm{MWT}_{\text {time }} \\
\text { total }\end{array}$ & All & 858/842/796 & $14.5[11.3,19.0]$ & $16.8[9.8]$ & $11.4[9.0,15.0]$ & $13.1[5.9]$ & $17.2[0.0,32.9]$ & $15.5[29.4]$ \\
\hline $\begin{array}{l}10 \mathrm{MWT}_{\text {time }} \\
\text { women }\end{array}$ & All & $344 / 339 / 319$ & $15.5[12.9,20.9]$ & $18.1[10.6]$ & $12.3[10.0,16.0]$ & $13.9[6.2]$ & $18.2[0.0,34.5]$ & $17.1[27.1]$ \\
\hline $\begin{array}{l}10 \mathrm{MWT} \\
\text { men }\end{array}$ & All & $514 / 503 / 477$ & $14.0[11.0,18.0]$ & $15.9[9.2]$ & $11.0[9.0,14.5]$ & $12.6[5.6]$ & $16.7[0.0,31.3]$ & $14.5[30.8]$ \\
\hline \multicolumn{9}{|l|}{ Stratified by age } \\
\hline $\mathrm{TUG}_{\text {time }}$ total & $<70$ & 259 & $17.0[13.0,24.0]$ & 19.6 [9.9] & $12.0[9.5,16.0]$ & $14.2[7.6]$ & $25.0[9.1,40.8]$ & $22.7[31.3]$ \\
\hline TUG ${ }_{\text {time }}$ total & $70 \leq x<80$ & 759 & $18.5[14.0,25.4]$ & $22.0[12.4]$ & $14.0[11.0,19.0]$ & $16.7[9.5]$ & $21.9[3.7,36.4]$ & $17.6[32.6]$ \\
\hline $\mathrm{TUG}_{\text {time }}$ total & $\geq 80$ & 231 & $23.0[17.0,30.0]$ & $25.6[12.5]$ & $19.0[14.7,24.0]$ & $20.7[8.7]$ & $14.3[0.0,32.2]$ & $11.9[32.9]$ \\
\hline TUG steps total & $<70$ & $254 / 258 / 254$ & $21.0[16.8,28.0]$ & $23.7[10.3]$ & $16.5[14.0,21.0]$ & $18.5[7.5]$ & $20.0[5.9,31.6]$ & $17.0[26.6]$ \\
\hline $\mathrm{TUG}_{\text {steps }}$ total & $70 \leq x<80$ & 746/756/741 & $23.0[18.0,30.0]$ & $25.8[11.2]$ & $19.0[15.0,24.0]$ & $20.9[8.7]$ & $17.4[3.5,31.3]$ & $14.8[26.7]$ \\
\hline TUG steps total & $\geq 80$ & 229/229/226 & $26.0[21.0,33.0]$ & $29.4[12.4]$ & $23.0[18.0,29.0]$ & $24.9[9.4]$ & $11.3[-3.4,26.7]$ & $10.4[25.3]$ \\
\hline \multicolumn{9}{|l|}{ Outliers } \\
\hline TUG $_{\text {time }}$ outliers & All & 51 & $91.0[58.0,122.0]$ & 96.7 [54.3] & $40.0[25.8,90.0]$ & $62.2[52.4]$ & $53.1[-47.1,75.0]$ & $-3.4[140.1]$ \\
\hline $\mathrm{TUG}_{\text {steps }}$ outliers & All & $49 / 51 / 49$ & $82.0[59.5,97.5]$ & $85.2[46.2]$ & $40.0[29.0,68.0]$ & $52.9[30.5]$ & $44.0[-4.0,66.3]$ & $22.1[61.2]$ \\
\hline $\begin{array}{l}\text { TUG }_{\text {time }} \text { all } \\
\text { including } \\
\text { outliers }\end{array}$ & All & 1300 & $19.0[14.0,27.3]$ & $25.1[21.5]$ & $14.8[11.0,21.0]$ & $18.7[16.3]$ & $22.2[2.5,38.2]$ & $16.6[43.2]$ \\
\hline $\begin{array}{l}\text { TUG }_{\text {steps }} \text { all } \\
\text { including } \\
\text { outliers }\end{array}$ & All & $1277 / 1294 / 1273$ & $23.0[18.0,31.0]$ & $28.2[18.3]$ & $19.0[15.0,26.0]$ & 22.4 [12.3] & $17.2[0.0,31.6]$ & $14.5[29.5]$ \\
\hline
\end{tabular}

Pre- and post-operative values of $\mathrm{TUG}_{\text {time, }} \mathrm{TUG}_{\text {steps }}$ and $10 \mathrm{MWT}_{\text {time }}$ in all patients and by sex and age groups. All post-operative changes were significantly different

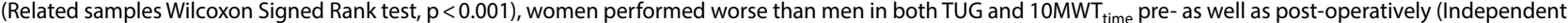
samples Mann-Whitney $U$ test, $p<0.001$ ) and the younger age groups performed better on the TUG test than the older ones (Independent samples Kruskal-Wallis test and Independent samples Mann-Whitney $U$ test, $\mathrm{p}<0.001$ ) 


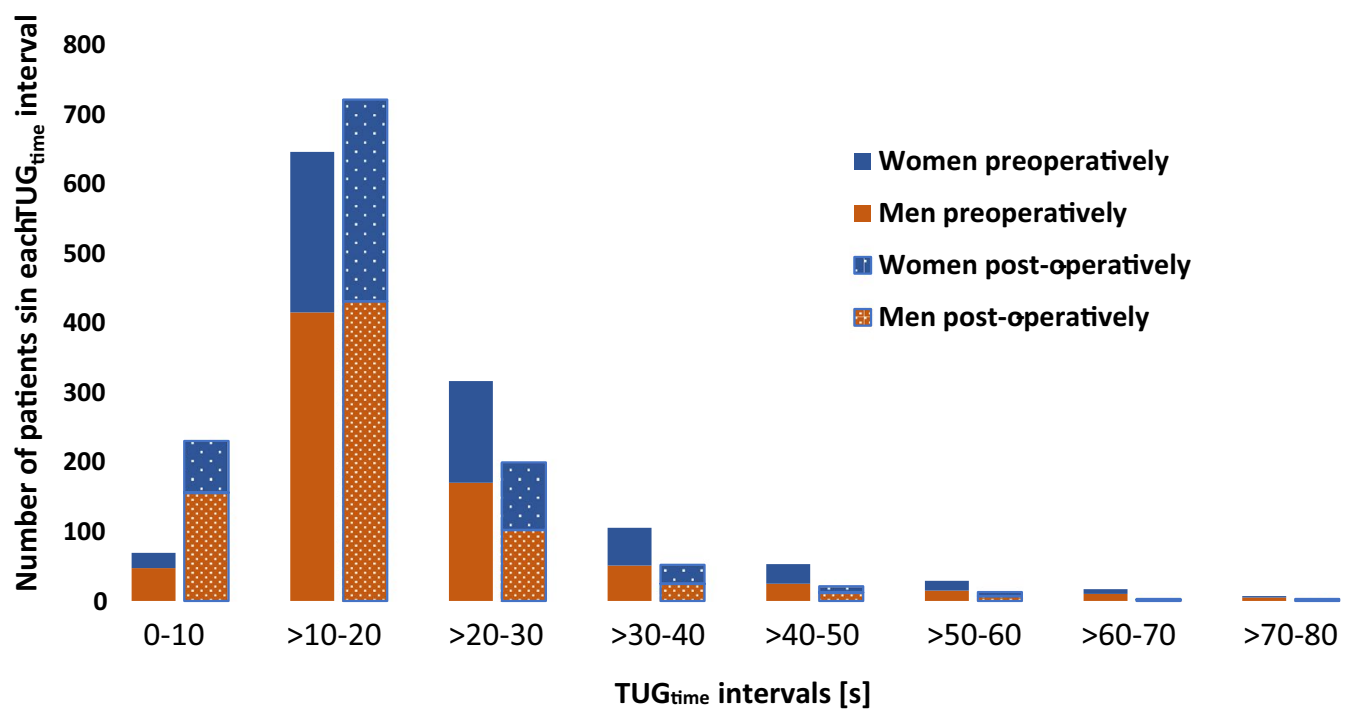

Fig. 2 Histogram displaying the number of patients within each TUG $G_{\text {time }}$ interval pre- and post-operatively for men $(n=744)$ and women $(n=505)$. Preoperatively, 175 men and 79 women had $\mathrm{TUG}_{\text {time }}<13.5$ s. Post-operatively the corresponding numbers were 364 and 186. Above this threshold the risk of falling is considered to be increased [23]

and 10MWT for the general patient group, overall as well as when stratified for sex or age. In Fig. 2, the number of patients in all intervals with $\mathrm{TUG}_{\text {time }}>20 \mathrm{~s}$ was fewer after surgery, while the number of patients with $\mathrm{TUG}_{\text {time }} 0-20 \mathrm{~s}$ was increased 3 months after surgery. Pre- as well as post-operatively, women performed significantly worse than men in both TUG and 10MWT $(\mathrm{p}<0.001)$ but there were no differences in post-operative improvement rates. Preoperatively, the younger age groups performed significantly better in $\mathrm{TUG}_{\text {time }}$ and $\mathrm{TUG}_{\text {steps }}$ than the older ones $(\mathrm{p}<0.001)$. In the group of outliers, where preoperative $T_{U} G_{\text {time }}$ and $T U G_{\text {steps }}$ were higher (i.e. worse performance) by construction, median level of post-operative improvement was much higher than in the main group (Table 2). The outliers only marginally affected the TUG values and levels of improvement when included in the main group, however (Table 2).

When patients were dichotomised based on their preoperative $\mathrm{TUG}_{\text {time }}$ and the threshold for increased risk of falling (Group 1: $\mathrm{TUG}_{\text {time }}<13.5 \mathrm{~s}$, group 2: TUG time $\geq 13.5 \mathrm{~s})$, the median (Q1, Q3) improvement in TUG time was larger in seconds (Group 1: $1.0(-1.0,2.5) \mathrm{s}$, group 2: $5.0(1.7,9.5) \mathrm{s}$ ) as well as percentage (Group 1: 8.3 (- 9.1, 22.2) \%, group 2: $25.0(8.3,40.6) \%$ ) for the group with an increased risk of falling $(\mathrm{p}<0.001)$. Pre- and post-operatively, 254 (20.3\%) and 550 (44.0\%) patients had $\mathrm{TUG}_{\text {time }}<13.5 \mathrm{~s}$, respectively.

The correlations between pre- and post-operative TUG time and $\mathrm{TUG}_{\text {steps }}$ and the $10 \mathrm{MWT}, \mathrm{miNPH}, \mathrm{mRS}$ and MMSE scales are shown in Table 3. A strong relationship was seen between TUG and the 10MWT both pre- and

Table 3 Correlations between outcome measures

\begin{tabular}{|c|c|c|c|c|c|c|c|c|}
\hline \multirow[t]{3}{*}{ Rating scales } & \multicolumn{4}{|c|}{ Preoperatively } & \multicolumn{4}{|c|}{ Post-operatively } \\
\hline & \multicolumn{2}{|c|}{ TUG $_{\text {time }}$} & \multicolumn{2}{|c|}{ TUG $_{\text {steps }}$} & \multicolumn{2}{|c|}{ TUG $_{\text {time }}$} & \multicolumn{2}{|c|}{ TUG $_{\text {steps }}$} \\
\hline & $\mathbf{n}$ & $\mathbf{R}$ & $\mathbf{n}$ & $\mathbf{R}$ & $\mathrm{n}$ & $\mathbf{R}$ & $n$ & $\mathbf{R}$ \\
\hline $10 \mathrm{MWT} \mathrm{T}^{\mathrm{a}}$ & 858 & 0.80 & 817 & 0.80 & 843 & 0.84 & 828 & 0.83 \\
\hline miNPH scale & 1242 & -0.61 & 1222 & -0.55 & 1248 & -0.71 & 1242 & -0.66 \\
\hline mRS & 1223 & 0.45 & 1203 & 0.40 & 1197 & 0.56 & 1191 & 0.53 \\
\hline MMSE & 1189 & -0.28 & 1174 & -0.26 & 1181 & -0.30 & 1177 & -0.26 \\
\hline
\end{tabular}

a $10 \mathrm{MWT}$ is measured in $\mathrm{s}$ when correlated to TUGtime and in steps when compared to TUGsteps

Correlations (Spearman's rho) between pre- and post-operative TUG $_{\text {time }}$ and TUG $_{\text {steps }}$ against the 10MWT, miNPH, mRS and MMSE scales. All correlations were statistically significant 
post-operatively, while the relationship was moderate with the miNPH scale, weak to moderate with mRS and negligible with MMSE $(\mathrm{p}<0.05)$.

The correlations between post-operative changes in TUG time and steps against the changes in 10MWT, miNPH, mRS and MMSE scales are shown in Table 4. A strong relationship was seen between $\mathrm{TUG}_{\text {time }}$ and TUG steps. Apart from this, all correlations were negligible to moderate although all were significant.

\section{Discussion}

The novel findings of this study are the description of patients' performance and post-operative change following shunt surgery of the TUG test in the largest population of non-selected iNPH patients yet reported. Median preoperative TUG time/steps of $19 \mathrm{~s} / 23$ steps were found, with significantly higher (worse) values in women compared to men. After surgery, TUG time and steps were significantly improved independent of sex and in all age groups. The improvement was generally greater for patients with worse preoperative performance and patients of younger age. High correlations were seen between TUG and 10MWT both pre- and post-operatively. However, when correlating changes due to surgery (i.e., paired differences between preoperative and postoperative assessments in each outcome measure), there were only low or moderate correlations between TUG and the other outcome measures including the 10MWT.

At baseline, iNPH patients had a median $\mathrm{TUG}_{\text {time }}$ of $19 \mathrm{~s}$. The TUG test has been developed as an easy and useful test for measuring physical mobility in the frail elderly population and provides information about gait speed, balance control, cognitive function, and functional capacity $[11,25,26]$. Originally, only execution time $\left(\mathrm{TUG}_{\text {time }}\right)$ was described as the outcome measure of the TUG test, but in our study the number of steps $\left(\mathrm{TUG}_{\text {steps }}\right)$ required to finish the walk was also analysed to reveal any possible differences between measurement metrics. A meta-analysis including 21 studies investigating the TUG test in healthy elderly persons resulted in mean TUG times of 8.1 (95\% CI 7.1-9.0) s, $9.2(8.2-10.2) \mathrm{s}$ and $11.3(10.0-12.7) \mathrm{s}$ for 60-69, 70-79 and 80-99 year olds, respectively [27]. In the present study, the iNPH patients performed worse in the TUG test than healthy elderly, in all age groups preoperatively as well as post-operatively, a finding that corroborates earlier reports by Agerskov et al. (median TUG time $=17 \mathrm{~s}, \mathrm{n}=247)$ [18] and Yamada et al. (26\% of 151 patients with $\mathrm{TUG}_{\text {time }}<15 \mathrm{~s}$ ) [15]. The higher TUG times indicate that the test captures the disturbances consistent with the gait dysfunction of iNPH regardless of age, and that the symptoms are not completely normalised 3 months post-operatively, reinforcing the notion that iNPH causes a severe, harmful functional impairment. The optimal time for shunt surgery in iNPH is not settled but early treatment is probably preferable as it gives patients a chance to recover to a higher functional level [28].

The TUG test has been used to predict the risk of falling, and a TUG time $\geq 13.5 \mathrm{~s}$ has been suggested as a cut-off to identify potential fallers [23]. In this study, this threshold is exceeded in many iNPH patients, indicating a high risk of falling $[29,30]$, which also corresponds with our clinical experience and previous findings that a history of falls is frequently reported by patients at the time of diagnosis [31, 32]. Patients with preoperative $\mathrm{TUG}_{\text {time }} \geq 13.5 \mathrm{~s}$ improved significantly more in numerals as well as percentage, suggesting that there is a lot to benefit regarding regained stability in this patient group. The proportion of patients having a $\mathrm{TUG}_{\text {time }}<13.5 \mathrm{~s}$ also increased from 20 to $44 \%$ post-operatively, however, more than half of the patients still had TUG times indicating a high risk of future falls post-operatively. Previously it has also been found that the TUG test as a single instrument is not sensitive enough to differentiate fallers from non-fallers in patients with mild gait disturbance. Combining the TUG test with a dynamic balance test, e.g., the Functional Gait Assessment, which estimates the ability to maintain postural stability during provocation of gait, was suggested in these patients [30].

Table 4 Correlations between post-operative changes in clinical scales

\begin{tabular}{|c|c|c|c|c|c|c|c|c|c|c|}
\hline \multirow[t]{2}{*}{ Group } & \multicolumn{2}{|c|}{$\Delta$ TUG $_{\text {steps }}$} & \multicolumn{2}{|c|}{$\Delta 10 M W T^{\mathrm{a}}$} & \multicolumn{2}{|c|}{$\Delta \mathrm{miNPH}$} & \multicolumn{2}{|c|}{$\Delta \mathrm{mRS}$} & \multicolumn{2}{|c|}{$\Delta$ MMSE } \\
\hline & $\mathrm{n}$ & $\mathbf{R}$ & $n$ & $\mathbf{R}$ & $n$ & $\mathbf{R}$ & $n$ & $\mathbf{R}$ & $\mathrm{n}$ & $R$ \\
\hline$\Delta T U G_{\text {time }}$ & 1226 & 0.76 & 796 & 0.60 & 1241 & 0.34 & 1174 & 0.22 & 1131 & 0.17 \\
\hline$\Delta T U G_{\text {steps }}$ & & & 777 & 0.61 & 1218 & 0.33 & 1151 & 0.23 & 1113 & 0.18 \\
\hline$\triangle 10 \mathrm{MWT}$ & & & & & 794 & 0.37 & 744 & 0.25 & 727 & 0.16 \\
\hline$\triangle \mathrm{miNPH}$ & & & & & & & 1166 & 0.35 & 1124 & 0.14 \\
\hline$\triangle \mathrm{mRS}$ & & & & & & & & & 1079 & 0.11 \\
\hline
\end{tabular}

Correlations (Spearman's rho) between post-operative change in $\mathrm{TUG}_{\text {time, }} \mathrm{TUG}_{\text {steps }}$ and 10MWT, miNPH, mRS and MMSE. All correlations were statistically significant. $\Delta=$ Pre/post difference, $n=$ number of patients and $R=$ correlation constant

a $10 \mathrm{MWT}$ is measured in $\mathrm{s}$ when correlated to all scales but $\mathrm{TUG}_{\text {steps }}$ when it is measured in steps. All correlations were statistically significant 
Women performed significantly worse than men in the TUG test, which is in line with other studies among community-dwelling older adults that aimed to establish normative data of older adults [33,34]. Older men still have better muscle strength than women of corresponding ages, possibly explaining some of the gender differences of the test [35]. Ibrahim et al. found that there were also differences in the TUG test between persons with and without hypertension, heart disease, joint pain, hearing and vision problems and urinary incontinence [34]. The sex distribution of these conditions is skewed, which may explain the differences between sexes seen in this study.

Cognitive impairment is also associated with worse performance on the TUG test [36, 37], but in this study the correlation between performance on the TUG test and MMSE was negligible (Tables 3, 4). Extended versions of the TUG test, with subtraction while walking and carrying a full cup of water (TUG dual task), have been developed in order to catch additional cognitive and physical aspects of the test to a greater extent [23]. The overall high TUG times in this large, unselected patient group, with significantly worse performance for women than men corroborates previous reports [38] and again raises the question of whether the diagnosis of iNPH is generally found at a later than necessary stage where the symptom development has progressed.

As could be expected, and importantly for the TUG test to be valuable in the outcome assessment of iNPH, TUG was significantly improved post-operatively. One larger study previously investigated the average values of the TUG test in 247 patients with iNPH. Median (IQR) TUG times of 17 (12-24) and $12(10-17) \mathrm{s}$ (pre- and post-operatively) were found [18], which was comparable to the current study. Post-operatively, median improvement was the same among sexes. This was contradictory to the outcome of the European multicentre study, where women improved significantly more than men [38]. A possible explanation could be that the population in the European multicentre study was smaller and more selective, and thus not as representative for the whole iNPH population as in our study.

The outputs of the TUG test are not normally distributed in this iNPH population. While most patients have $\mathrm{TUG}_{\text {time }}$ and $\mathrm{TUG}_{\text {steps }}$ in the range 15-30 s/steps, there is a lower boundary for how fast a person can get up, walk $6 \mathrm{~m}$ and sit down again, but not an upper boundary regarding how long time it may take to perform the test. This results in a positive/right skewed distribution with a few patients with extremely long test times or number of steps. The rational for presenting data separately for those with $\mathrm{TUG}_{\text {time }}$ or $\mathrm{TUG}_{\text {steps }}>80 \mathrm{~s} / \mathrm{steps}$, considered to be outliers, was that we did not want these extreme cases to affect the overall picture of the general population. In the outlier group, median improvement was substantially higher (proportionately and in absolute numbers) than for the main group, supporting the view that patients with severe symptomatology should not be excluded from surgery. This was favoured by Agerskov et al. who found no association between symptom severity and outcome [18], although challenged by Kimura et al. who reported a negative association between symptom severity and outcome [39]. Notably, the outliers in our study still had considerably higher TUG values postoperatively, indicative of a substantially sustained gait impairment despite the large improvement.

The TUG test is widely used in the elderly population and in other neurodegenerative disorders such as Parkinson's disease (PD) [40]. Patients with iNPH may have some motor features in common with PD. It can be confusing when a patient with a clinical appearance compatible with PD has a radiological picture which can best be explained by iNPH. In PD, TUG can be used to differentiate between early and middle stage disease [41], and also between subtypes of PD, namely tremor-dominant and postural instability-gait difficulty-dominant [42]. For iNPH, important differential diagnoses are parkinsonism due to cerebral small vessel disease and atypical parkinsonian disorders. Here, bilateral motor impairment affecting the lower extremities is a common symptom. Vascular small vessel disease as seen in vascular parkinsonism nearly always co-exists with iNPH, which makes the picture more complex. Atypical parkinsonism (ATP), causing diagnostic difficulties, are multiple system atrophy (MSA) and progressive supranuclear palsy (PSP). In a recent study, patients with MSA and PSP had similar mean (SD) TUG times (18 (6.5) s and 22.4 (15.5) $\mathrm{s}$ respectively) as the iNPH patients in the current study (22.2 (12.1) s) while patients with idiopathic PD and stable doses of dopaminergic ( $\mathrm{L}$-dopa) therapy had faster TUG times (12 (3.4) s) [43]. The effect of L-dopa on the TUG test was also reported in another study where PD patients on and off L-dopa had TUG times of 20.2 (12.6) $\mathrm{s}$ and 15.4 (5.2) s, respectively [44]. This effect of L-dopa closely resembles the treatment effect of shunt surgery in iNPH with pre- and post-operative TUG times of $22.2 \mathrm{~s}$ and $16.9 \mathrm{~s}$, respectively.

The changes in the TUG test post-operatively compared to preoperatively were only negligibly to moderately correlated to the changes in the other scales, although the correlations were statistically significant. The correlations were strongest $(r=0.60-0.61)$ between the changes in the TUG and the 10TMWT tests, which could be expected since these measures evaluate the same domain to the largest extent. A small study investigating the TUG test as a diagnostic criterion in iNPH yielded similar, very weak correlations among the TUG 
test, the Japanese grading scale and the MMSE [45]. There may be several reasons for this. For instance, a patient that is clinically improved according to the miNPH scale or mRS is not necessarily improved in balance control and/or gait, which would be required for improvement in the TUG test. It was suggested that the poor correlations could come from the different nature of the scoring methods since the output of a TUG test can range between a few seconds and several minutes, while the ordinal scales of the other tests have a much smaller maximum range. Thus, a large standard deviation is more likely in the TUG test compared to the ordinal scales [45]. Another possible reason is that the TUG test measures other functional aspects than the other outcome scales, i.e. it is a valuable complement to outcome assessment for iNPH patients.

When comparing TUG to the 10MWT, the high preand post-operative correlations confirm that both tests identify similar levels of gait and balance impairment in individual subjects. The reduced relationship when comparing post-operative differences (i.e. low correlation between post-operative change in each scale, respectively) infers, however, that post-operative improvement is not straightforwardly translatable between the outcome measures.

\section{Strengths and limitations of the study}

Strengths of this study are the large sample of iNPH patients included, the nationwide coverage, the use of established measures of clinical function and outcome and stratification for age and sex.

Since information on the 10MWT could only be collected from four out of the seven surgical centres, the group of patients with information on the 10MWT was smaller than the others. Compared to other studies, however, this is still a large body of material that we believe reflects the general and unselected iNPH population.

A consequence of the non-selected inclusion of all patients with iNPH undergoing shunt surgery at SHQR centres in Sweden between 2010 and 2020, was that the time point of the preoperative assessment in relation to the shunt surgery could not be predetermined. Instead, it was dependent on each centres resources and waiting times for surgery over the years. Thus, even though all postoperative assessments were performed approximately 3 months after surgery, the total time between initial and follow-up examinations varied between centres and over time.

The use of the miNPH scale instead of the iNPH scale was a limitation. The original scale is more comprehensive than the miNPH scale, but we were limited by the data available in the SHQR at the time of inclusion. Since improvement in iNPH patients after surgery is seen predominately in the gait and/or balance domain, the exclusion of the neuropsychological tests should pose a smaller problem. The exclusion of the 10MWT can make outcome assessment by the miNPH scale blunter than the original scale since only ordinal scales are included. It is also limiting that the SHQR only includes patients that are operated on due to hydrocephalus, no information is registered on subjects not operated on following their investigation for iNPH. Nor does the registry include any data following the cerebrospinal fluid tap test performed as part of the diagnostic procedure in many subjects. Thus, the difference in the TUG test between subjects being/not being selected for shunt surgery and the TUG test in relation to the predictive value of the tap test for a positive outcome following shunt surgery could not be investigated.

The main limitation of this study is that there is no universal and well-established measure for determining the "true" clinical outcome of each patient. Thus, and as shown in this study, each outcome scale evaluated its own aspects of the disorder, and it is hard to say which scale is most relevant to the patient or if all scales are of equal value. In this study we compare the most common measures incorporating gait, balance, and general performance level to reveal existing similarities and differences among them.

\section{Conclusion}

The outcome of the TUG test of patients with iNPH are worse than those of healthy elderly and comparable to those of patients with PD. The significant improvement following surgery implies that the TUG test captures clinical features that commonly improve in patients with iNPH following surgery. The TUG time and steps were significantly higher in women than in men, but the rate of improvement was the same between the sexes. Patients with higher preoperative TUG times improved more, and for groups with comparable preoperative TUG times, younger patients improved more. Even though the correlation with the 10MWT was strong pre- and post-operatively, correlations of postoperative change with the 10MWT and other scales were only low to moderate. This suggests that the inclusive nature of the TUG test may offer additional value when assessing the effects of shunt surgery.

\section{Abbreviations}

ATP: Atypical Parkinsonism; 10MWT: 10-Meter walk test; iNPH: Idiopathic normal pressure hydrocephalus; IQR: Interquartile range; miNPH: Scalemodified iNPH scale; MMSE: Mini Mental State Examination; mRS: Modified Rankin Scale; MSA: Multiple system atrophy; PSP: Progressive supranuclear palsy; r: Correlation coefficient; SD: Standard deviation; SHQR: Swedish Hydrocephalus Quality Registry; TUG :Timed up and go. 


\section{Acknowledgements}

The authors wish to acknowledge the Swedish Hydrocephalus Quality Registry for supplying data for the study.

\section{Authors' contributions}

NS, FL and MT designed the study, all authors contributed to the data collection and NS performed the statistical analyses of the data. NS drafted the manuscript and all authors provided critical feedback and helped shape the research and analysis as well as revise and finalise the manuscript. All authors read and approved the final manuscript.

\section{Funding}

Open access funding provided by Umea University. Funding was received from the Rune and Ulla Amlöv foundation, the Edit Jacobson foundation, the Hjalmar Svenssons foundation and the Swedish state under the agreement between the Swedish government and the county councils, the ALF-agreement (\#ALFGBG 720121).

\section{Availability of data and materials}

The datasets used and/or analysed during the current study are available from the corresponding author on reasonable request.

\section{Declarations}

\section{Ethics approval and consent to participate}

The regional ethical review board in Umeå approved the study (Dnr 2018444-31M). In accordance with Swedish legislation and regulations regarding patient consent for participation in a national quality registry, patients are informed about their inclusion in the registry before undergoing surgery. They can opt out of inclusion at any time.

\section{Consent for publication}

Not applicable.

\section{Competing interests}

Mats Tullberg has received an honorarium for lecturing from Codman, Integra. The other authors declare that they have no competing interests.

\section{Author details}

'Department of Radiation Sciences, Radiation Physics, Biomedical Engineering, Umeå University, Umeå, Sweden. ${ }^{2}$ Department of Activity and Health, and Department of Biomedical and ClinicalSciences, Linköping University, Linköping, Sweden. ${ }^{3}$ Department of Neuroscience, Neurology, Uppsala University, Uppsala, Sweden. ${ }^{4}$ Department of Neurology, and Department of Biomedical and Clinical Sciences, Linköping University, Linköping, Sweden. ${ }^{5}$ Hydrocephalus Research Unit, Department of Clinical Neuroscience, Institute of Neuroscience and Physiology, The Sahlgrenska Academy, University of Gothenburg, Gothenburg, Sweden.

\section{Received: 1 October 2021 Accepted: 17 December 2021} Published online: 10 January 2022

\section{References}

1. Hakim S, Adams RD. The special clinical problem of symptomatic hydrocephalus with normal cerebrospinal fluid pressure. Observations on cerebrospinal fluid hydrodynamics. J Neurol Sci. 1965;2(4):307-27.

2. Andersson J, Rosell M, Kockum K, Lilja-Lund O, Soderstrom L, Laurell K. Prevalence of idiopathic normal pressure hydrocephalus: a prospective, population-based study. PLoS ONE. 2019;14(5):e0217705.

3. Martin-Laez R, Caballero-Arzapalo H, Valle-San Roman N, Lopez-Menendez LA, Arango-Lasprilla JC, Vazquez-Barquero A. Incidence of idiopathic normal-pressure hydrocephalus in Northern Spain. World Neurosurg. 2016;87:298-310.

4. Toma AK, Papadopoulos MC, Stapleton S, Kitchen ND, Watkins LD. Systematic review of the outcome of shunt surgery in idiopathic normalpressure hydrocephalus. Acta Neurochir. 2013;155(10):1977-80.
5. Kubo Y, Kazui H, Yoshida T, Kito Y, Kimura N, Tokunaga H, et al. Validation of grading scale for evaluating symptoms of idiopathic normal-pressure hydrocephalus. Dement Geriatr Cogn Disord. 2008;25(1):37-45.

6. Stein SC, Langfitt TW. Normal-pressure hydrocephalus. Predicting the results of cerebrospinal fluid shunting. J Neurosurg. 1974;41(4):463-70.

7. Hellstrom P, Klinge P, Tans J, Wikkelso C. A new scale for assessment of severity and outcome in iNPH. Acta Neurol Scand. 2012;126(4):229-37.

8. van Swieten JC, Koudstaal PJ, Visser MC, Schouten HJ, van Gijn J. Interobserver agreement for the assessment of handicap in stroke patients. Stroke. 1988;19(5):604-7.

9. Folstein MF, Folstein SE, McHugh PR. "Mini-mental state". A practical method for grading the cognitive state of patients for the clinician. J Psychiatr Res. 1975;12(3):189-98.

10. Malm J, Kristensen B, Karlsson T, Fagerlund M, Elfverson J, Ekstedt J. The predictive value of cerebrospinal fluid dynamic tests in patients with th idiopathic adult hydrocephalus syndrome. Arch Neurol. 1995;52(8):783-9.

11. Podsiadlo D, Richardson S. The timed "Up \& Go": a test of basic functional mobility for frail elderly persons. J Am Geriatr Soc. 1991;39(2):142-8.

12. Herman T, Giladi N, Hausdorff JM. Properties of the 'timed up and go' test: more than meets the eye. Gerontology. 2011;57(3):203-10.

13. Viccaro $L$, Perera S, Studenski SA. Is timed up and go better than gait speed in predicting health, function, and falls in older adults? J Am Geriatr Soc. 2011;59(5):887-92.

14. Barry E, Galvin R, Keogh C, Horgan F, Fahey T. Is the timed up and go test a useful predictor of risk of falls in community dwelling older adults: a systematic review and meta-analysis. BMC Geriatr. 2014;14:14.

15. Yamada S, Ishikawa M, Miyajima M, Nakajima M, Atsuchi M, Kimura T, et al. Timed up and go test at tap test and shunt surgery in idiopathic normal pressure hydrocephalus. Neurol Clin Pract. 2017;7(2):98-108.

16. Yamada S, Aoyagi Y, Yamamoto K, Ishikawa M. Quantitative evaluation of gait disturbance on an instrumented timed up-and-go test. Aging Dis. 2019;10(1):23-36.

17. Ishikawa M, Yamada S, Yamamoto K, Aoyagi Y. Gait analysis in a component timed-up-and-go test using a smartphone application. J Neurol Sci. 2019;398:45-9.

18. Agerskov S, Hellstrom P, Andren K, Kollen L, Wikkelso C, Tullberg M. The phenotype of idiopathic normal pressure hydrocephalus-a single center study of 429 patients. J Neurol Sci. 2018;391:54-60.

19. Sundstrom N, Lagebrant M, Eklund A, Koskinen LD, Malm J. Subdural hematomas in 1846 patients with shunted idiopathic normal pressure hydrocephalus: treatment and long-term survival. J Neurosurg. 2018;129(3):797-804.

20. Sundstrom N, Malm J, Laurell K, Lundin F, Kahlon B, Cesarini KG, et al. Incidence and outcome of surgery for adult hydrocephalus patients in Sweden. Br J Neurosurg. 2017;31(1):21-7.

21. Andren K, Wikkelso C, Sundstrom N, Agerskov S, Israelsson H, Laurell K, et al. Long-term effects of complications and vascular comorbidity in idiopathic normal pressure hydrocephalus: a quality registry study. J Neurol. 2018;265(1):178-86.

22. Relkin N, Marmarou A, Klinge P, Bergsneider M, Black PM. Diagnosing idiopathic normal-pressure hydrocephalus. Neurosurgery. 2005;57(3 Suppl):S4-16 (discussion ii-v).

23. Shumway-Cook A, Brauer S, Woollacott M. Predicting the probability for falls in community-dwelling older adults using the Timed Up \& Go Test. Phys Ther. 2000;80(9):896-903.

24. Mukaka MM. Statistics corner: a guide to appropriate use of correlation coefficient in medical research. Malawi Med J. 2012;24(3):69-71.

25. Mirelman A, Weiss A, Buchman AS, Bennett DA, Giladi N, Hausdorff JM. Association between performance on Timed Up and Go subtasks and mild cognitive impairment: further insights into the links between cognitive and motor function. J Am Geriatr Soc. 2014;62(4):673-8.

26. McGough EL, Kelly VE, Logsdon RG, McCurry SM, Cochrane BB, Engel JM, et al. Associations between physical performance and executive function in older adults with mild cognitive impairment: gait speed and the timed "up \& go" test. Phys Ther. 2011;91(8):1198-207.

27. Bohannon RW. Reference values for the timed up and go test: a descriptive meta-analysis. J Geriatr Phys Ther. 2006;29(2):64-8.

28. Andren K, Wikkelso C, Hellstrom P, Tullberg M, Jaraj D. Early shunt surgery improves survival in idiopathic normal pressure hydrocephalus. Eur J Neurol. 2021;28(4):1153-9. 
29. Nikaido Y, Urakami H, Akisue T, Okada Y, Katsuta N, Kawami Y, et al. Associations among falls, gait variability, and balance function in idiopathic normal pressure hydrocephalus. Clin Neurol Neurosurg. 2019;183:105385.

30. Nikaido Y, Kajimoto Y, Akisue T, Urakami H, Kawami Y, Kuroda K, et al. Dynamic balance measurements can differentiate patients who fall from patients who do not fall in patients with idiopathic normal pressure hydrocephalus. Arch Phys Med Rehabil. 2019;100(8):1458-66.

31. Nikaido Y, Akisue T, Urakami H, Kajimoto Y, Kuroda K, Kawami Y, et al. Postural control before and after cerebrospinal fluid shunt surgery in idiopathic normal pressure hydrocephalus. Clin Neurol Neurosurg. 2018;172:46-50.

32. Selge C, Schoeberl F, Zwergal A, Nuebling G, Brandt T, Dieterich M, et al. Gait analysis in PSP and NPH: dual-task conditions make the difference. Neurology. 2018;90(12):e1021-8.

33. Coelho-Junior HJ, Uchida MC, Goncalves IO, Calvani R, Rodrigues B, Picca A, et al. Age- and gender-related changes in physical function in community-dwelling Brazilian adults aged 50 to 102 years. J Geriatr Phys Ther. 2021;44(2):E123-31.

34. Ibrahim A, Singh DKA, Shahar S. 'Timed Up and Go'test: age, gender and cognitive impairment stratified normative values of older adults. PLoS ONE. 2017;12(10):e0185641.

35. Reid KF, Doros G, Clark DJ, Patten C, Carabello RJ, Cloutier GJ, et al. Muscle power failure in mobility-limited older adults: preserved single fiber function despite lower whole muscle size, quality and rate of neuromuscular activation. Eur J Appl Physiol. 2012;112(6):2289-301.

36. Donoghue OA, Horgan NF, Savva GM, Cronin H, O'Regan C, Kenny RA. Association between timed up-and-go and memory, executive function, and processing speed. J Am Geriatr Soc. 2012;60(9):1681-6.

37. Liu Y, Ma W, Li M, Han P, Cai M, Wang F, et al. Relationship between physical performance and mild cognitive impairment in Chinese communitydwelling older adults. Clin Interv Aging. 2021;16:119-27.

38. Klinge P, Hellstrom P, Tans J, Wikkelso C. European i NPHMSG. One-year outcome in the European multicentre study on iNPH. Acta Neurol Scand. 2012;126(3):145-53.

39. Kimura T, Yamada S, Sugimura T, Seki T, Miyano M, Fukuda S, et al. Preoperative predictive factors of short-term outcome in idiopathic normal pressure hydrocephalus. World Neurosurg. 2021;151:e399-406.

40. Bloem BR, Marinus J, Almeida Q, Dibble L, Nieuwboer A, Post B, et al. Measurement instruments to assess posture, gait, and balance in Parkinson's disease: critique and recommendations. Mov Disord. 2016;31(9):1342-55.

41. Dewey DC, Miocinovic S, Bernstein I, Khemani P, Dewey RB 3rd, Querry $\mathrm{R}$, et al. Automated gait and balance parameters diagnose and correlate with severity in Parkinson disease. J Neurol Sci. 2014;345(1-2):131-8.

42. Herman T, Weiss A, Brozgol M, Giladi N, Hausdorff JM. Identifying axial and cognitive correlates in patients with Parkinson's disease motor subtype using the instrumented Timed Up and Go. Exp Brain Res. 2014;232(2):713-21.

43. Borm C, Krismer F, Wenning GK, Seppi K, Poewe W, Pellecchia MT, et al. Axial motor clues to identify atypical parkinsonism: a multicentre European cohort study. Parkinsonism Relat Disord. 2018;56:33-40.

44. Dibilio V, Nicoletti A, Mostile G, Toscano S, Luca A, Raciti L, et al. Dopaminergic and non-dopaminergic gait components assessed by instrumented timed up and go test in Parkinson's disease. J Neural Transm (Vienna). 2017;124(12):1539-46.

45. Mendes GAS, de Oliveira MF, Pinto FCG. The timed up and go test as a diagnostic criterion in normal pressure hydrocephalus. World Neurosurg. 2017;105:456-61.

\section{Publisher's Note}

Springer Nature remains neutral with regard to jurisdictional claims in published maps and institutional affiliations.
Ready to submit your research? Choose BMC and benefit from:

- fast, convenient online submission

- thorough peer review by experienced researchers in your field

- rapid publication on acceptance

- support for research data, including large and complex data types

- gold Open Access which fosters wider collaboration and increased citations

- maximum visibility for your research: over 100M website views per year

At BMC, research is always in progress.

Learn more biomedcentral.com/submissions 